\title{
Risk of second primary malignancy in adults with pulmonary high-grade neuroendocrine carcinoma (HGNEC)
}

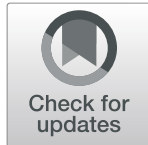

\author{
Xiaomin $\mathrm{Wu}^{1}$, Xiaojing Zhang ${ }^{2}$, Leilei Tao ${ }^{1}$ and Ping Chen $^{1^{*}}$ (D)
}

\begin{abstract}
Background: Pulmonary high-grade neuroendocrine carcinoma (HGNEC) has a rising incidence of developing second primary malignancies (SPMs). This study is the first population-based analysis to quantify the SPM risks among survivors of lung HGNEC.

Methods: We used the Surveillance, Epidemiology, and End Results (SEER) database to calculate standardized incidence ratio (SIR) and absolute excess risk (AER) between 2000 and 2016 for patients with pulmonary HGNEC.

Results: The data of 1161 patients with SPMs were retrieved from the SEER database. The ratio of observed/ expected number of SPMs in pulmonary HGNEC was 1.53. Solid tumours comprised $91 \%$ of all second malignancies in lung HGNEC patients, with the most common cancers reported in the oral cavity and pharynx, the urinary and respiratory systems
\end{abstract}

Conclusions: Our study observed an increased risk of SPMs among patients with pulmongnancies.

\section{Background}

Lung cancer is one of the most frequently diagnosed cancers and the leading cause of cancer death in the United States $[1,2]$. Pulmonary high-grade neuroendocrine carcinoma (HGNEC), including small cell lung cancer (SCLC) and large cell neuroendocrine carcinoma (LCNEC), is a heterogeneous group of poorly differentiated neoplasms and covers $20 \%$ of all lung cancers. Remarkably, these two subtypes have relatively similar histological, genetic, and clinical characteristics, such as higher incidence in males and heavy smokers, as well as high mitotic rate and necrosis at histologic examination. It is also widely believed that they have similarly poor overall survival [3].

\footnotetext{
* Correspondence: pingchen_yc@163.com

'Department of Oncology, Yancheng No.1 People's Hospital, the Affiliated Hospital of Nanjing University, 166 Yulong West Road, Yancheng 224200, People's Republic of China

Full list of author information is available at the end of the article
}

Cancer survivors have been increasing due to the improvement in diagnostic modalities and treatment of cancers. Second primary malignancy (SPM) is one of the most severe long-term complications in the population of cancer survivors. Several studies have demonstrated that patients with initial primary lung cancer have a higher risk of developing second primary lung cancer [4]. According to research done by $\mathrm{Wu}$ and coworkers, the incidence of SPMs among patients with non-small cell lung cancer is about $6.4 \%$. Furthermore, their findings indicated that $50.7 \%$ of SPMs occurred during the first year after the diagnosis of non-small cell lung cancer [5]. However, the risk of SPMs following a diagnosis of lung HGNEC remains unclear.

In this context, we aimed to assess the risk of developing SPM in patients with pulmonary HGNEC in the United States utilizing the Surveillance, Epidemiology, and End Results (SEER) database. We obtained the standardized incidence ratio (SIR) of SPM after diagnosis of pulmonary HGNEC between January 2000 and 
December 2016. The incidence of SPMs stratified by age, sex, race, and latency was also analyzed. Additionally, multivariate Cox regression model was applied to investigate the factors affecting overall survival (OS) and cancer-specific survival (CSS) in patients with SPMs.

\section{Methods}

We obtained data on lung HGNEC patients from the SEER database, which collects cancer incidence and survival data from 18 regional cancer registries. These registries represent about $26 \%$ of the U.S. population. Using a 6-month minimum interval, as is required to exclude synchronous primary cancers, we identified cases of histologically confirmed HGNEC with primary site codes (C34.0-main bronchus; C34.1-upper lobe, lung; C34.2middle lobe, lung; C34.3-lower lobe, lung; C34.8-overlapping lesion of the lung; and C34.9-lung, NOS) and ICD-0-3 Hist/Behav (8002/3: malignant tumour, small cell type; 8013/3: Large-cell neuroendocrine carcinoma; 8041/3: small cell carcinoma, NOS; 8042/3: oat cell carcinoma; 8043/3: small cell carcinoma, fusiform cell; 8044/3: small cell carcinoma, intermediate cell; and 8045/3: combined small cell carcinoma). Patients with no histologically confirmed cancer, and those diagnosed only based on autopsy/death certificate were excluded as were those under the age of 20 years. After the exclusion of patients who did not have active follow-up, 75,877 patients were ultimately eligible for inclusion into the present investigation.

We collected data on patient demographics (age, gender, and ethnicity), treatment (radiotherapy and chemotherapy), HGNECs (cancer site and histological subtype) and survival (survival period, vital status, and causespecific death classification). We utilized SEER*Stat multiple primary-standardized incidence ratio (MP-SIR) software version 8.3.5 (www.seer.cancer.gov/seerstat), to calculate the SIR and absolute excess risk (AER) for SPM occurrence. An SPM is defined as a metachronous cancer that develops at least 6 months after the first cancer diagnosis, according to the methods used previously. We estimated SIR as the ratio of the number of incident cases of cancers in patients with pulmonary HGNEC to the number of expected cases in the U.S. general population. SIR over 1.0 indicated that more cases were observed than would be expected. AER was calculated as the excess number of SPMs in patients with pulmonary HGNEC per 10,000 person-years at risk. We performed subgroup analyses by further stratifying patients according to their age at diagnosis, gender, ethnicity, calendaryears, and months of follow-up since the diagnosis of cancer.

Multivariate Cox regression analyses, which could identify the associations between different clinical characteristics and survival, were performed to estimate hazard ratios (HRs) and the associated 95\% confidence intervals (CIs). All statistical tests were two-sided, and $P$ values less than 0.05 were assumed to be significant. Our data were obtained from the SEER program and imported into SPSS software, and data analyses were performed using IBM SPSS statistics for Windows, version 23 (IBM Corp, Armonk, New York, USA).

\section{Results}

Between 2000 and 2016, 75,877 patients were diagnosed with pulmonary HGNEC and met inclusion criteria. 72, 381 patients with small cell carcinoma and 3496 patients with large-cell neuroendocrine carcinoma were included. A total of 1161 cases with primary pulmonary HGNEC, including 1022 SCLC and 139 LCNEC, developed a cohort of 1361 SPMs. Among those with SMPs, 979 patients had only $1 \mathrm{SPM}$, and 182 had more than 2 SPMs. The demographic characteristics of both groups are displayed in Table 1.

\section{Overall risk of SPM}

This cohort had a trend of higher SPM incidence than expected in the general population (SIR 1.53; 95\% CI, 1.45 to 1.62; AER 83.11). Site-specific analyses of SIRs indicated the highest risk of malignancy in the acute monocytic leukemia (SIR 10.51; 95\% CI, 2.86 to 26.92), followed by acute myeloid leukemia (SIR 6.62; 95\% CI, 4.85 to 8.83 ), acute non-lymphocytic leukemia (SIR 6.46; 95\% CI, 4.8 to 8.52), oropharynx (SIR 6.24; 95\% CI, 2.03 to 14.57), and acute lymphocytic leukemia (SIR 5.26; 95\% CI, 1.43 to 13.46). However, AER was the highest for the respiratory system (AER 88.64), followed by digestive system (AER 10.85), and myeloid and monocytic leukemia (AER 7.81). The risk of developing SPM in patients with SCLC and LCNEC are summarized in Table 2.

A significantly increased risk was seen for different malignancies among two histology groups. Patients with SCLC were at excess risk of developing digestive system cancers (SIR 1.35; 95\% CI, 1.17 to 1.54 ) and respiratory system cancers (SIR 4.29; 95\% CI, 3.95 to 4.66). Similar risk trends were observed, where patients with pulmonary LCNEC had statistically significant excess risk for the development of the digestive system and respiratory system cancers. In the histology-specific analysis, the risk of the oral cavity and pharynx, urinary system and all lymphatic and hematopoietic diseases was not significantly influenced in LCNEC patients and increased in SCLC cases.

The risk of second cancers following lung HGNEC was higher for women than men $(\mathrm{SIR}=1.78[95 \% \mathrm{CI}=$ 1.65 to 1.91 ] versus 1.32 [95\% $\mathrm{CI}=1.22$ to 1.43$]$ ), and women had the highest SIR values irrespective of any race. SIR values decreased with age, with the uppermost SIR reported for the youngest (age $<50$ years) male 
Table 1 Demographics of patients

\begin{tabular}{|c|c|c|c|c|}
\hline & \multicolumn{4}{|l|}{ Demography } \\
\hline & \multicolumn{2}{|l|}{ SCLC } & \multicolumn{2}{|l|}{ LCNEC } \\
\hline & Number/Median & $\% /$ Range & Number/Median & $\% /$ Range \\
\hline Total patients & 72,381 & & 3496 & \\
\hline \multicolumn{5}{|l|}{ Sex } \\
\hline Male & 36,406 & $50.30 \%$ & 1928 & $55.15 \%$ \\
\hline Female & 35,975 & $49.70 \%$ & 1568 & $44.85 \%$ \\
\hline \multicolumn{5}{|l|}{ Race } \\
\hline White & 63,192 & $87.30 \%$ & 2919 & $83.50 \%$ \\
\hline Black & 6284 & $8.68 \%$ & 423 & $12.10 \%$ \\
\hline Other/unknown & 2905 & $4.01 \%$ & 154 & $4.41 \%$ \\
\hline Total patients with SPM & 1022 & $1.41 \%$ & 139 & $3.98 \%$ \\
\hline \multicolumn{5}{|l|}{ Sex } \\
\hline Male & 458 & $44.81 \%$ & 68 & $48.92 \%$ \\
\hline Female & 564 & $55.19 \%$ & 71 & $51.08 \%$ \\
\hline \multicolumn{5}{|l|}{ Race } \\
\hline White & 899 & $87.96 \%$ & 113 & $81.29 \%$ \\
\hline Black & 85 & $8.32 \%$ & 19 & $13.67 \%$ \\
\hline Other/unknown & 38 & $3.72 \%$ & 7 & $5.04 \%$ \\
\hline Patients with 1 SPM & 862 & $1.20 \%$ & 117 & $3.35 \%$ \\
\hline \multicolumn{5}{|l|}{ Sex } \\
\hline Male & 384 & $44.55 \%$ & 57 & $48.72 \%$ \\
\hline Female & 478 & $55.45 \%$ & 60 & $51.28 \%$ \\
\hline \multicolumn{5}{|l|}{ Race } \\
\hline White & 755 & $87.59 \%$ & 96 & $82.05 \%$ \\
\hline Black & 74 & $8.58 \%$ & 15 & $12.82 \%$ \\
\hline Other/unknown & 33 & $3.83 \%$ & 6 & $5.13 \%$ \\
\hline Patients with 2 or more SPM & 160 & $0.23 \%$ & 22 & $0.63 \%$ \\
\hline \multicolumn{5}{|l|}{ Sex } \\
\hline Male & 74 & $46.25 \%$ & 11 & $50 \%$ \\
\hline Female & 86 & $53.75 \%$ & 11 & $50 \%$ \\
\hline \multicolumn{5}{|l|}{ Race } \\
\hline White & 143 & $89.38 \%$ & 17 & $77.27 \%$ \\
\hline Black & 12 & $7.50 \%$ & 4 & $18.18 \%$ \\
\hline Other/unknown & 5 & $3.12 \%$ & 1 & $4.55 \%$ \\
\hline Age for SPM (median) & 64 years & (36-88 years) & 66 years & (37-82 years) \\
\hline Latency (median) & 3.58 years & (0.5-16.42 years) & 3.33 years & (0.67-15 years) \\
\hline Follow-up (median) & 5.42 years & (0.5-16.92 years) & 5.92 years & (0.67-15.75 years) \\
\hline
\end{tabular}

cohort (SIR 5.21; 95\% CI, 2.92 to 8.60). For men and women, SIR values increased with the year of initial primary lung HGNEC diagnosis (Table 3 ).

\section{Race and age at diagnosis}

All 3 race groups (white, black, and other) were at increased risk of SPM development (white: SIR 1.52, 95\%
CI, 1.43 to 1.61; black: SIR 1.56, 95\% CI, 1.29 to 1.86 ; and other: SIR 1.97, 95\% CI, 1.47 to 2.59 ). The risks of SPMs in the respiratory system were elevated across all race groups (Table 4). Whites were found to have a significantly elevated risk of SPM of the floor of mouth (SIR 8.11; 95\% CI, 3.50 to 15.98), and oropharynx (SIR 5.90; $95 \% \mathrm{CI}, 1.61$ to 15.09 ). In the black racial subgroup, 
Table 2 Total SPM

\begin{tabular}{|c|c|c|c|c|c|c|c|c|c|c|c|c|c|c|c|}
\hline \multirow[t]{2}{*}{ Site } & \multicolumn{5}{|c|}{ All cancers } & \multicolumn{5}{|c|}{ small cell lung cancer } & \multicolumn{5}{|c|}{ large cell neuroendocrine cancer } \\
\hline & $\mathrm{O}$ & $E$ & $\mathrm{O} / \mathrm{E}$ & $95 \% \mathrm{Cl}$ & $\begin{array}{l}\text { Excess } \\
\text { risk }\end{array}$ & $\mathrm{O}$ & E & $\mathrm{O} / \mathrm{E}$ & $95 \% \mathrm{Cl}$ & $\begin{array}{l}\text { Excess } \\
\text { risk }\end{array}$ & $\mathrm{O}$ & E & O/E & $95 \% \mathrm{Cl}$ & Excess risk \\
\hline All sites & 1361 & 887.49 & 1.53 & $1.45-1.62$ & 83.11 & 1195 & 804.21 & 1.49 & $1.4-1.57$ & 75.28 & 166 & 83.27 & 1.99 & $1.7-2.32$ & 163.46 \\
\hline All solid tumours & 1241 & 790.41 & 1.57 & $1.48-1.66$ & 79.08 & 1083 & 716.6 & 1.51 & $1.42-1.6$ & 70.58 & 158 & 73.81 & 2.14 & $1.82-2.5$ & 166.34 \\
\hline Oral cavity and pharynx & 30 & 20.08 & 1.50 & $1.01-2.13$ & 1.74 & 28 & 18.1 & 1.55 & $1.03-2.24$ & 1.91 & 2 & 1.97 & 1.02 & $0.12-3.68$ & 0.07 \\
\hline $\begin{array}{l}\text { Floor of Mouth, and Gum } \\
\text { and Other Mouth }\end{array}$ & 13 & 4.08 & 3.19 & $1.7-5.45$ & 1.57 & 13 & 3.69 & 3.52 & $1.88-6.02$ & 1.79 & 0 & 0.39 & 0.00 & $0.00-9.54$ & -0.76 \\
\hline Pharynx & 8 & 2.86 & 2.79 & $1.21-5.51$ & 0.9 & 7 & 2.58 & 2.71 & $1.09-5.58$ & 0.85 & 1 & 0.28 & 3.59 & 0.09-20.02 & 1.43 \\
\hline Digestive System & 227 & 165.17 & 1.37 & $1.2-1.57$ & 10.85 & 201 & 149.43 & 1.35 & $1.17-1.54$ & 9.93 & 26 & 15.75 & 1.65 & $1.08-2.42$ & 20.26 \\
\hline Esophagus & 17 & 9.32 & 1.82 & $1.06-2.92$ & 1.35 & 16 & 8.39 & 1.91 & $1.09-3.1$ & 1.47 & 1 & 0.94 & 1.06 & $0.03-5.93$ & 0.12 \\
\hline Colon and Rectum & 113 & 84.02 & 1.34 & $1.11-1.62$ & 5.09 & 100 & 76.28 & 1.31 & $1.07-1.59$ & 4.57 & 13 & 7.74 & 1.68 & $0.89-2.87$ & 10.39 \\
\hline $\begin{array}{l}\text { Anus, Anal Canal and } \\
\text { Anorectum }\end{array}$ & 8 & 3.19 & 2.51 & $1.08-4.94$ & 0.84 & 5 & 2.9 & 1.72 & $0.56-4.02$ & 0.4 & 3 & 0.29 & 10.44 & $2.15-30.5$ & 5.36 \\
\hline Pancreas & 46 & 25.96 & 1.77 & $1.3-2.36$ & 3.52 & 41 & 23.42 & 1.75 & $1.26-2.38$ & 3.39 & 5 & 2.54 & 1.97 & $0.64-4.59$ & 4.85 \\
\hline Respiratory System & 650 & 144.98 & 4.48 & $4.15-4.84$ & 88.64 & 564 & 131.35 & 4.29 & $3.95-4.66$ & 83.34 & 86 & 13.63 & 6.31 & $5.05-7.79$ & 142.99 \\
\hline Larynx & 20 & 6.92 & 2.89 & $1.77-4.46$ & 2.3 & 19 & 6.25 & 3.04 & $1.83-4.75$ & 2.46 & 1 & 0.67 & 1.48 & $0.04-8.26$ & 0.64 \\
\hline Lung and Bronchus & 627 & 136.6 & 4.59 & $4.24-4.96$ & 86.07 & 543 & 123.79 & 4.39 & $4.03-4.77$ & 80.75 & 84 & 12.82 & 6.55 & $5.23-8.12$ & 140.65 \\
\hline Breast & 86 & 122.17 & 0.70 & $0.56-0.87$ & -6.35 & 74 & 112.39 & 0.66 & $0.52-0.83$ & -7.39 & 12 & 9.78 & 1.23 & $0.63-2.14$ & 4.38 \\
\hline Female Breast & 86 & 121.11 & 0.71 & $0.57-0.88$ & -6.16 & 74 & 111.44 & 0.66 & $0.52-0.83$ & -7.21 & 12 & 9.67 & 1.24 & $0.64-2.17$ & 4.61 \\
\hline Female Genital System & 20 & 47.09 & 0.42 & $0.26-0.66$ & -4.76 & 19 & 43.35 & 0.44 & $0.26-0.68$ & -4.69 & 1 & 3.74 & 0.27 & $0.01-1.49$ & -5.42 \\
\hline Corpus and Uterus, NOS & 4 & 26.93 & 0.15 & $0.04-0.38$ & -4.02 & 4 & 24.8 & 0.16 & $0.04-0.41$ & -4.01 & 0 & 2.13 & 0.00 & $0-1.73$ & -4.21 \\
\hline Male Genital System & 59 & 144.85 & 0.41 & $0.31-0.53$ & -15.07 & 49 & 130.36 & 0.38 & $0.28-0.5$ & -15.67 & 10 & 14.49 & 0.69 & $0.33-1.27$ & -8.87 \\
\hline Prostate & 57 & 143.35 & 0.40 & $0.3-0.52$ & -15.16 & 47 & 129.02 & 0.36 & $0.27-0.48$ & -15.8 & 10 & 14.33 & 0.70 & $0.33-1.28$ & -8.56 \\
\hline Urinary System & 117 & 76.03 & 1.54 & $1.27-1.84$ & 7.19 & 104 & 68.35 & 1.52 & $1.24-1.84$ & 6.87 & 13 & 7.68 & 1.69 & $0.9-2.89$ & 10.51 \\
\hline Urinary Bladder & 68 & 45.07 & 1.51 & $1.17-1.91$ & 4.02 & 59 & 40.43 & 1.46 & $1.11-1.88$ & 3.58 & 9 & 4.64 & 1.94 & $0.89-3.68$ & 8.61 \\
\hline Kidney and Renal Pelvis & 47 & 28.99 & 1.62 & $1.19-2.16$ & 3.16 & 43 & 26.15 & 1.64 & $1.19-2.21$ & 3.25 & 4 & 2.84 & 1.41 & $0.38-3.61$ & 2.3 \\
\hline $\begin{array}{l}\text { All Lymphatic and } \\
\text { Hematopoietic Diseases }\end{array}$ & 95 & 75.86 & 1.25 & $1.01-1.53$ & 3.36 & 88 & 68.46 & 1.29 & $1.03-1.58$ & 3.76 & 7 & 7.41 & 0.95 & $0.38-1.95$ & -0.8 \\
\hline Lymphoma & 24 & 38.88 & 0.62 & $0.4-0.92$ & -2.61 & 23 & 35.14 & 0.65 & $0.41-0.98$ & -2.34 & 1 & 3.74 & 0.27 & $0.01-1.49$ & -5.41 \\
\hline Myeloma & 5 & 13.46 & 0.37 & $0.12-0.87$ & -1.49 & 4 & 12.12 & 0.33 & $0.09-0.84$ & -1.56 & 1 & 1.34 & 0.75 & $0.02-4.15$ & -0.68 \\
\hline Leukemia & 66 & 23.52 & 2.81 & $2.17-3.57$ & 7.46 & 61 & 21.19 & 2.88 & $2.2-3.7$ & 7.67 & 5 & 2.33 & 2.15 & $0.7-5.01$ & 5.28 \\
\hline
\end{tabular}

${ }^{*} \mathrm{O}$, observed numbers; $\mathrm{E}$, expected numbers

the risk of an SPM was highest in the adrenal gland (SIR 41.01; $95 \% \mathrm{CI}, 1.04$ to 228.51 ), followed by gum and other mouth (SIR 9.10; 95\% CI, 1.10 to 32.89), and esophagus (SIR 4.50; 95\% CI, 1.23 to 11.52). In the other racial subgroup, the risk of developing an SPM in the digestive system was not significantly altered (SIR 0.66; 95\% CI, 0.21 to 1.54), but their risk of SPMs for oropharynx was markedly increased (SIR 69.80; 95\% CI, 1.77 to 388.92$)$.

Overall risk was negatively correlated with age (20-49 years: SIR $3.75,95 \%$ CI, 2.55 to 5.33 ; 50-64 years: SIR 1.84, 95\% CI, 1.66 to 2.03 ; $65+$ years: SIR 1.41, 95\% CI, 1.32 to 1.50 , Fig. 1). All 3 age groups had an elevated risk of developing SPMs in the digestive system and respiratory system (Table 5). Subgroup analysis suggested that younger patients had an increased risk of SPMs of the pancreas (SIR 41.88 ; $95 \%$ CI, 13.60 to 97.74 ), floor of mouth (SIR 81.76; 95\% CI, 2.07 to 455.51), gum and other mouth (SIR 40.99; 95\% CI, 1.04 to 228.4), and respiratory system (SIR 12.41; 95\% CI, 4.99 to 25.58). Older patients were at greater risk of malignancies of acute myeloid leukemia (SIR 5.65; 95\% CI, 3.87 to 7.98 ), floor of mouth (SIR 5.48; 95\% CI, 1.49 to 14.04), ascending colon (SIR 2.15; 95\% CI, 1.35 to 3.25), respiratory system (SIR 3.90; 95\% CI, 3.55 to 4.28 ), and urinary system (SIR 1.37; 95\% CI, 1.09 to 1.69).

\section{Histology}

Five hundred and eighty-two patients developed one or more second primary lung cancers (SPLCs). The 
Table 3 Standardized incidence ratio (SIR) analysis of SMP in patients with a history of an initial primary lung HGNEC by sex, race, age and year of diagnosis, SEER-18

\begin{tabular}{llllll}
\hline & Observed & Expected & O/E & $95 \% \mathrm{Cl}$ & Excess risk \\
\hline Total & 1361 & 887.49 & 1.53 & $1.45-1.62$ & 83.11
\end{tabular}

Age and Sex

Male

$\begin{array}{clllll}\text { All Men } & 619 & 469.98 & 1.32 & 1.22-1.43 & 59.83 \\ <50 & 15 & 2.88 & 5.21 & 2.92-8.60 & 100.27 \\ 50-64 & 187 & 106.35 & 1.76 & 1.52-2.03 & 83.72 \\ >65 & 417 & 360.75 & 1.16 & 1.05-1.27 & 39.99 \\ \begin{array}{c}\text { Female } \\ \text { All Women }\end{array} & 742 & 417.5 & 1.78 & 1.65-1.91 & 101.19 \\ <50 & 16 & 5.38 & 2.98 & 1.70-4.83 & 76.02 \\ 50-64 & 207 & 107.69 & 1.92 & 1.67-2.20 & 80.9 \\ >65 & 519 & 304.43 & 1.7 & 1.56-1.86 & 116.64\end{array}$

Sex and Race

Male

\begin{tabular}{llllll} 
White & 524 & 404.86 & 1.29 & $1.19-1.41$ & 56.6 \\
Black & 61 & 46.61 & 1.31 & $1.00-1.68$ & 60.13 \\
Other & 34 & 18.03 & 1.89 & $1.31-2.64$ & 111.65 \\
$\begin{array}{l}\text { Female } \\
\text { White }\end{array}$ & 663 & 377.18 & 1.76 & $1.63-1.90$ & 100.63 \\
Black & 61 & 31.78 & 1.92 & $1.47-2.47$ & 107.75 \\
Other & 18 & 8.31 & 2.17 & $1.28-3.42$ & 104.01 \\
Sex and Year & & & & & \\
Male & & & & & \\
2000-2004 & 57 & 85.79 & 0.66 & $0.50-0.86$ & -66.4 \\
2005-2010 & 230 & 184.25 & 1.25 & $1.09-1.42$ & 47.7 \\
2011-2016 & 332 & 199.94 & 1.66 & $1.49-1.85$ & 120.29 \\
Female & & & & & \\
$2000-2004$ & 63 & 62.86 & 1 & $0.77-1.28$ & 0.3 \\
$2005-2010$ & 239 & 157.77 & 1.51 & $1.33-1.72$ & 66.49 \\
$2011-2016$ & 440 & 196.87 & 2.23 & $2.03-2.45$ & 162.62 \\
\hline
\end{tabular}

various histological types of SPLC were assessed within each subset of the lung HGNEC (Table 6). Squamous cell carcinoma was the most common subtype, and a higher proportion was observed following SCLC. Conversely, initial primary LCNECs most presented with SPLC adenocarcinoma (40\%). Only 15\% of SPLCs were SCLC, which is similar to the incidence of SCLC in the general population. Among the study population, $74 \%$ of patients who developed SPLCs initially had regional and distant stage, but only $22 \%$ had localized stage. More than half of those SPLCs (55\%) presented at advanced or unknown stage, while only $45 \%$ had localized disease.

\section{SPM and latency}

The incidence of developing SPMs was relatively high after 12 months of lung HGNEC diagnosis and then increased, with significantly difference from that of the general population (Fig. 2). The risk of oropharyngeal cancer (SIR 9.22; 95\% CI, 1.12 to 33.31), and kidney cancer (SIR 2.24; 95\% CI, 1.28 to 3.63) was much higher within 6-11 months of the index diagnosis. However, no significant risk of SPM was found in other latency intervals. The risk of mouth floor cancer (SIR 6.90; 95\% CI, 1.88 to 17.66), leukemia (SIR 3.84; 95\% CI, 2.81 to 5.13), and ascending colon cancer (SIR 2.23; 95\% CI, 1.22 to 3.74) was greatly increased within $12-59$ months of latency compared to the general population. Significant increases in the risk for cancers of the digestive system and respiratory system also existed 12 months or more after the index diagnosis. The risk of SPM for each latency period is shown in Table 7.

\section{Overall survival and clinical characteristics}

Multivariate Cox proportional hazards model was performed to determine risk factors associated with overall survival and cancer-specific survival (Table 8). After adjusting for other factors, patients with regional and distant stage disease were much more likely to have an increased risk of death with HRs of 1.608 (95\% CI, 1.317 to $1.964 ; P=0.000$ ) and 2.113 (95\% CI, 1.716 to 2.602 ; $P=0.000$ ), respectively. Patients aged $\geq 65$ years had an elevated risk of death compared with those aged less than 65 years (HR 1.242; $95 \% \mathrm{CI}, 1.085$ to $1.422 ; P=$ 0.002). As for latency time, those patients shorter than 60 months also showed a difference in an elevated risk of death (HR 3.862; 95\% CI, 3.310 to $4.507 ; P=0.000$ ). Beam radiation (HR 1.997; 95\% CI, 1.233 to 3.237 ) was related to the worsening prognosis, but chemotherapy status did not have a significant association with overall survival. Variables that were significantly associated with increased cancer-specific mortality were beam radiation, regional/distant disease, and an interval of $<60$ months between the diagnosis of lung HGNEC.

\section{Discussion}

As far as we know, this study is the first to quantify the occurrence of SPMs after pulmonary HGNEC. Our study revealed that the overall risk of SPM in patients with pulmonary HGNEC was statistically higher than that in the general population. In total, the incidence of SMPs in patients with pulmonary HGNEC is approximately $1.53 \%$. The incidence of SPMs in patients with SCLC is $1.41 \%$, whereas the incidence in patients with lung LCNEC is $3.98 \%$. Going beyond prior researches, we estimated the risk of second malignancies by calculating SIRs, which were stratified by age, sex, race, latency, and histology. 
Table 4 Risk of SPM after lung HGNEC, stratified by race

\begin{tabular}{|c|c|c|c|c|c|}
\hline & Observed & Expected & $\mathrm{O} / \mathrm{E}$ & $95 \% \mathrm{Cl}$ & Excess risk \\
\hline \multicolumn{6}{|l|}{ White } \\
\hline All Sites & 1187 & 782.04 & 1.52 & $1.43-1.61$ & 81.89 \\
\hline All Solid Tumours & 1080 & 695.27 & 1.55 & $1.46-1.65$ & 77.8 \\
\hline Oral Cavity and Pharynx & 26 & 17.87 & 1.45 & $0.95-2.13$ & 1.64 \\
\hline Floor of Mouth & 8 & 0.99 & 8.11 & $3.5-15.98$ & 1.42 \\
\hline Oropharynx & 4 & 0.68 & 5.9 & $1.61-15.09$ & 0.67 \\
\hline Digestive System & 195 & 140.5 & 1.39 & $1.20-1.60$ & 11.02 \\
\hline Splenic Flexure & 5 & 1.6 & 3.13 & $1.02-7.30$ & 0.69 \\
\hline Pancreas & 40 & 22.39 & 1.79 & $1.28-2.43$ & 3.56 \\
\hline Respiratory System & 568 & 127.47 & 4.46 & $4.10-4.84$ & 89.08 \\
\hline Breast & 78 & 110.42 & 0.71 & $0.56-0.88$ & -6.56 \\
\hline Female Genital System & 17 & 42.44 & 0.4 & $0.23-0.64$ & -5.14 \\
\hline Male Genital System & 46 & 120.8 & 0.38 & $0.28-0.51$ & -15.13 \\
\hline Urinary System & 102 & 68.89 & 1.48 & $1.21-1.80$ & 6.7 \\
\hline Urinary Bladder & 62 & 41.77 & 1.48 & $1.14-1.90$ & 4.09 \\
\hline Kidney & 36 & 23.49 & 1.53 & $1.07-2.12$ & 2.53 \\
\hline All Lymphatic and Hematopoietic Diseases & 84 & 67.83 & 1.24 & $0.99-1.53$ & 3.27 \\
\hline Leukemia & 59 & 21.46 & 2.75 & $2.09-3.55$ & 7.59 \\
\hline \multicolumn{6}{|l|}{ Black } \\
\hline All Sites & 122 & 78.39 & 1.56 & $1.29-1.86$ & 85.42 \\
\hline All Solid Tumours & 114 & 70.91 & 1.61 & $1.33-1.93$ & 84.42 \\
\hline Oral Cavity and Pharynx & 2 & 1.55 & 1.29 & $0.16-4.67$ & 0.89 \\
\hline Gum and Other Mouth & 2 & 0.22 & 9.1 & $1.1-32.89$ & 3.49 \\
\hline Digestive System & 27 & 16.98 & 1.59 & $1.05-2.31$ & 19.62 \\
\hline Esophagus & 4 & 0.89 & 4.5 & $1.23-11.52$ & 6.09 \\
\hline Respiratory System & 54 & 13.17 & 4.1 & $3.08-5.35$ & 79.97 \\
\hline Male Genital System & 10 & 18.97 & 0.53 & $0.25-0.97$ & -17.58 \\
\hline Kidney & 7 & 2.74 & 2.55 & $1.03-5.26$ & 8.34 \\
\hline Adrenal Gland & 1 & 0.02 & 41.01 & $1.04-228.51$ & 1.91 \\
\hline Leukemia & 4 & 1.48 & 2.7 & $0.73-6.91$ & 4.93 \\
\hline \multicolumn{6}{|c|}{ Other (American Indian/AK Native, Asian/Pacific Islander) } \\
\hline All Sites & 52 & 26.33 & 1.97 & $1.47-2.59$ & 108.64 \\
\hline All Solid Tumours & 47 & 23.6 & 1.99 & $1.46-2.65$ & 99.04 \\
\hline Oral Cavity and Pharynx & 2 & 0.62 & 3.24 & $0.39-11.7$ & 5.85 \\
\hline Pharynx & 2 & 0.19 & 10.47 & $1.27-37.81$ & 7.66 \\
\hline Oropharynx & 1 & 0.01 & 69.8 & $1.77-388.92$ & 4.17 \\
\hline Digestive System & 5 & 7.56 & 0.66 & $0.21-1.54$ & -10.82 \\
\hline Respiratory System & 28 & 4.23 & 6.63 & $4.4-9.58$ & 100.62 \\
\hline Leukemia & 3 & 0.56 & 5.4 & $1.11-15.77$ & 10.34 \\
\hline
\end{tabular}

A significantly elevated risk of cancer in pulmonary HGNEC was also evident in our report, especially in patients aged less than 50 years, females, other races (American Indian/AK Native, Asian/Pacific Islander), patients with longer latency periods and LCNEC patients. The SIRs in females were found to be higher than their male counterparts, even though pulmonary HGNEC are less common in the female than male. It is estimated that the incidence of SCLC varied by gender, with a lower frequency in females. Survival was superior 


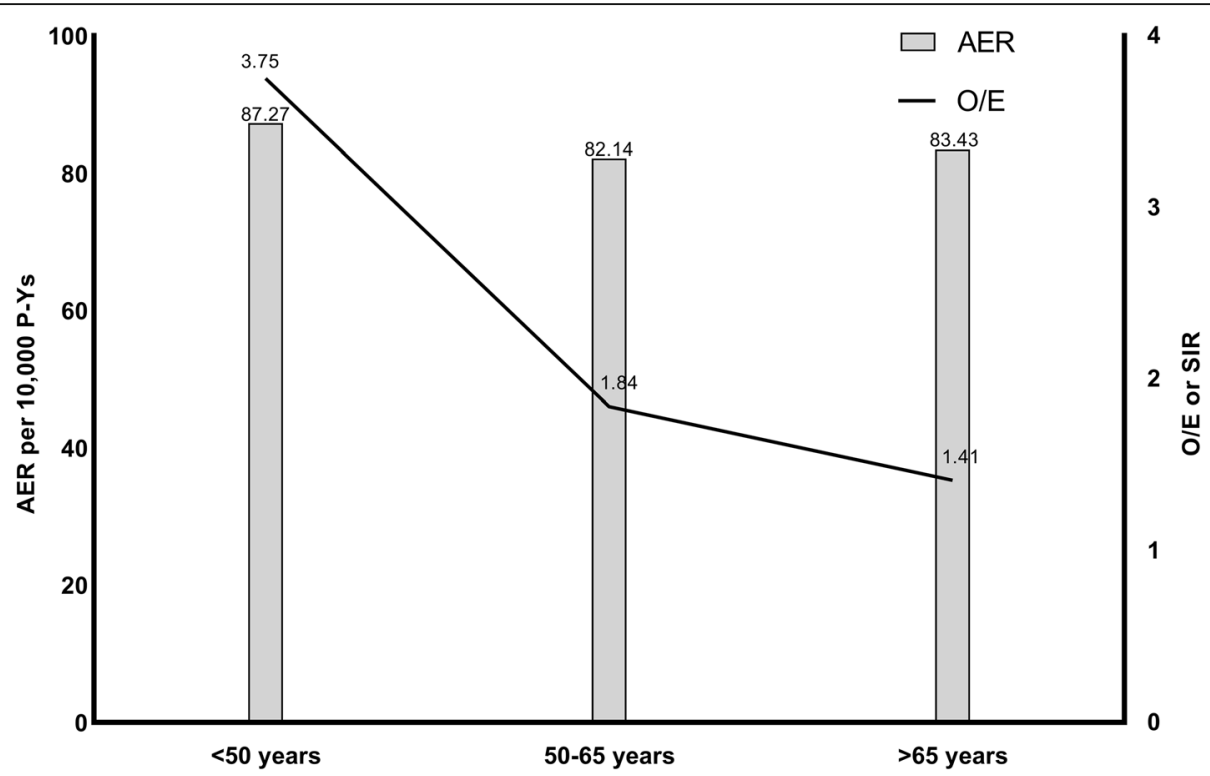

Fig. 1 Observed/expected (O/E) incidence and absolute excess rate (AER) for second primary malignancies (SPMs) by patient age at the time of lung HGNEC diagnosis

to women, indicating genomic incompatibility between the sexes [6]. Carcinogens in cigarette smoke have been hypothesized to preferentially bind to estrogen receptors, thereby inhibiting their carcinogen activation reactions [7]. Furthermore, it has been shown that the use of hormone replacement therapy decreased lung cancer risk in females, especially in female never smokers [8]. Females may be more likely to survive longer and have access to develop an SPM. These factors may potentially explain the higher SIRs and the lower risk of females. However, younger males had the highest SIR. This may be relevant to the declining overall cancer incidence among younger males. A review of the existing studies shows that there are twice as many women as men in younger cancer patients [9]. Thus, the difference between the observed and expected risk of developing cancers in younger males will be greater. Furthermore, the incidence of SPMs increased with age. These results confirmed those of Deng et al. who found increased age as a negative survival predictor in patients with LCNEC [10].

We observed that lung HGNEC survivors, particularly SCLC survivors, were less likely to develop cancers of the breast, female genital system, and prostate. In contrast, patients with lung HGNEC had elevated risks of getting leukemia and cancers of the oral cavity and pharynx, colon and rectum, esophagus, pancreas, urinary bladder, kidney and renal pelvis, and lung and bronchus. Cancer risk reduction in these patients is consistent with prior researches, which are relevant to lung cancer and non-small cell lung cancer $[11,12]$. Although the causes of risk reduction are not well understood, they may be associated with patient age at diagnosis of SCLC. The current incidence of SCLC was highest in the 65-79 age group, and the number of SCLC patients decreased in most age groups over the past few decades, primarily because of public awareness about smoking and comprehensive tobacco control programs [6]. Nevertheless, older patients who have SCLC may not have an equal opportunity for an SPM as the total population of the United States. Conversely, the increased rate of certain cancers following primary lung HGNEC seems to be attributed to smoking. Lung HGNEC patients had a greater risk of developing respiratory system cancer in all age groups. This correlation was also evident in a subgroup analysis of the younger populations below the age of 50 years.

Other considerations are more deliberate surveillance and molecular mutation. Once patients are newly diagnosed with cancer, they may receive more monitoring. In most lung HGNEC, only a few genes were found to be mutated regularly. Tumour suppressor protein 53 (TP53) and retinoblastoma 1 (RB1), which are strongly associated with smoking, are mutated in nearly all SCLC $[13,14]$ and most of these lung LCNEC [15]. Even so, no targeted therapy could be translated from basic research to standard treatment until now. Smoking is also a risk factor for HPV-negative head and neck squamous cell carcinoma. Mutations are more frequent in these tumours from smokers than non-smokers. TP53 mutations are more common in HPV-negative tumours and have been related to poor survival and therapeutic resistance [16]. This may be relevant to the increased rate of the oral cavity and pharynx cancer observed in our SCLC cohort, so patients with SCLC would necessarily be expected to have closer surveillance for these smoking- 


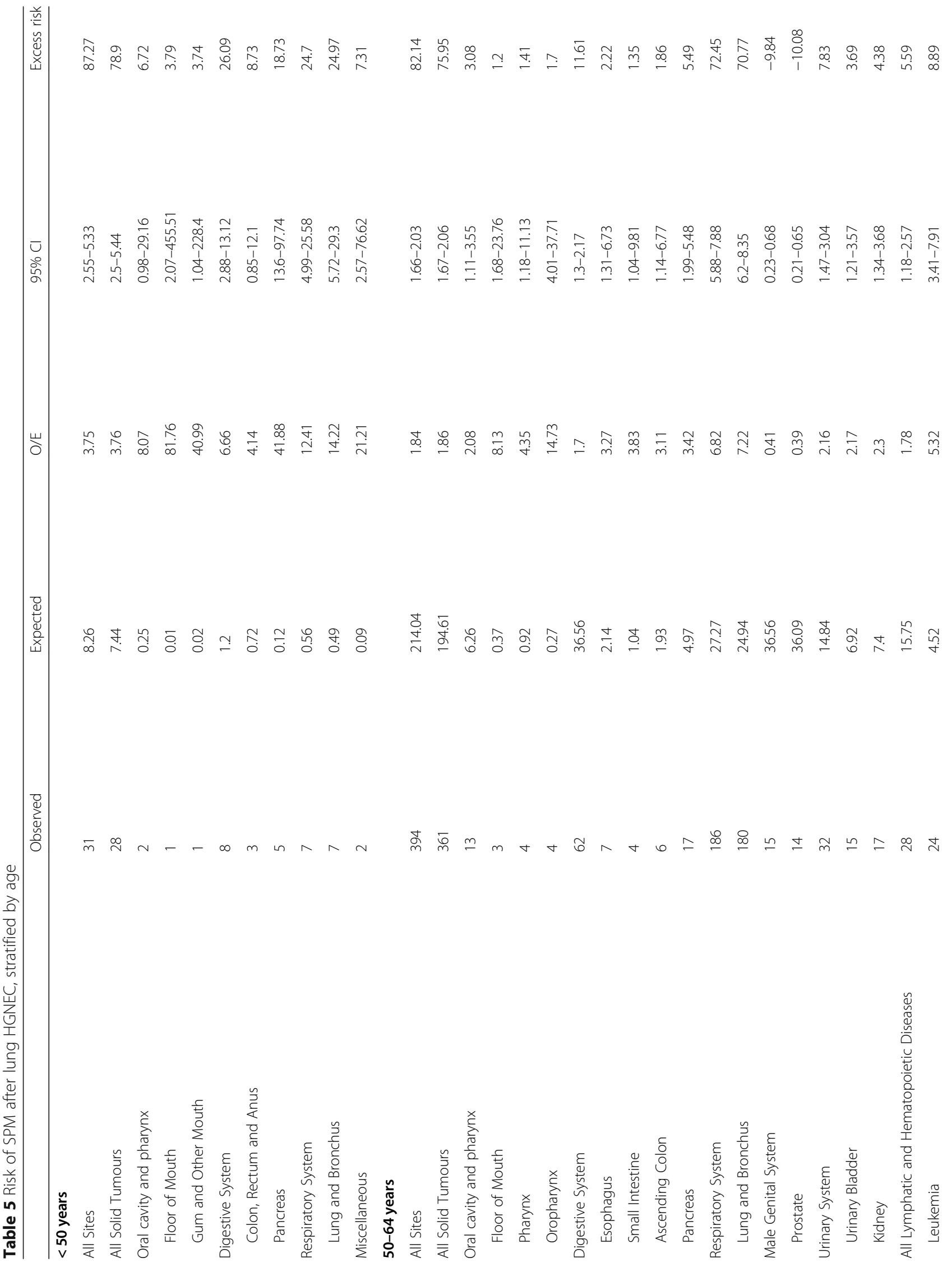




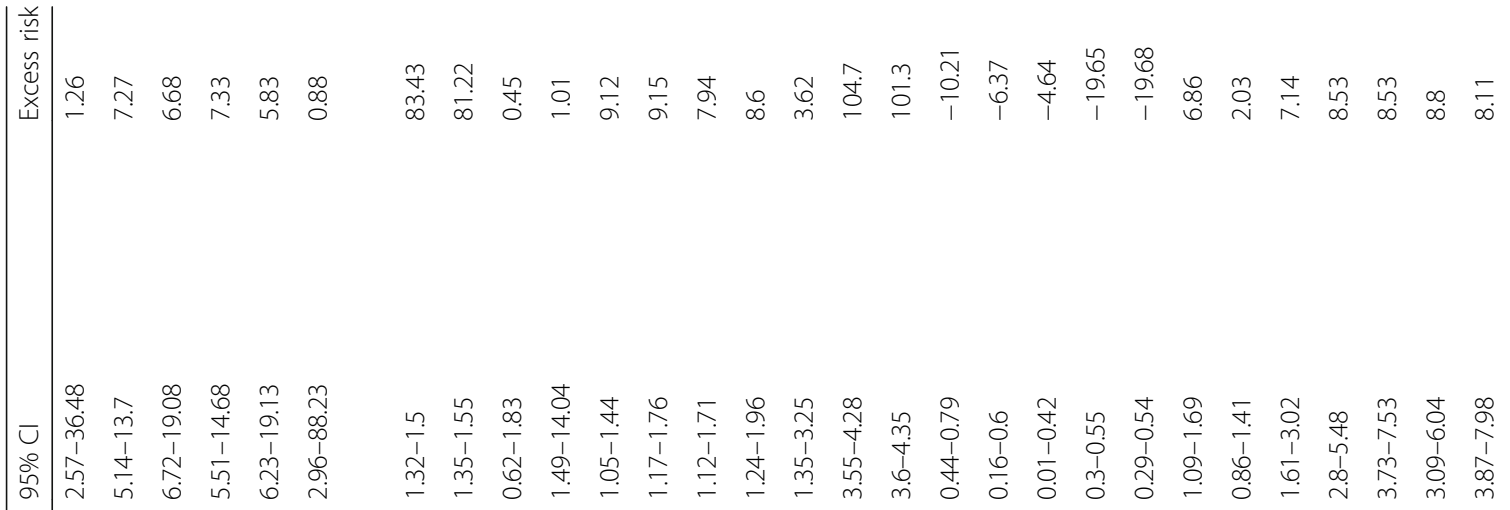

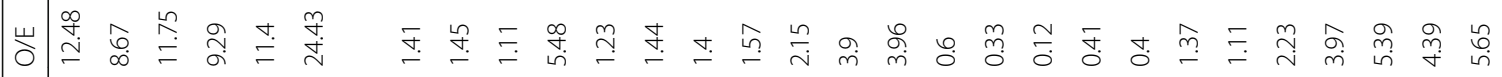

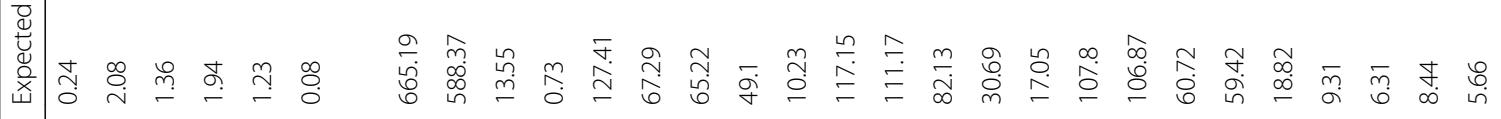

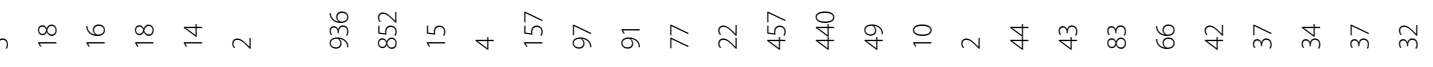
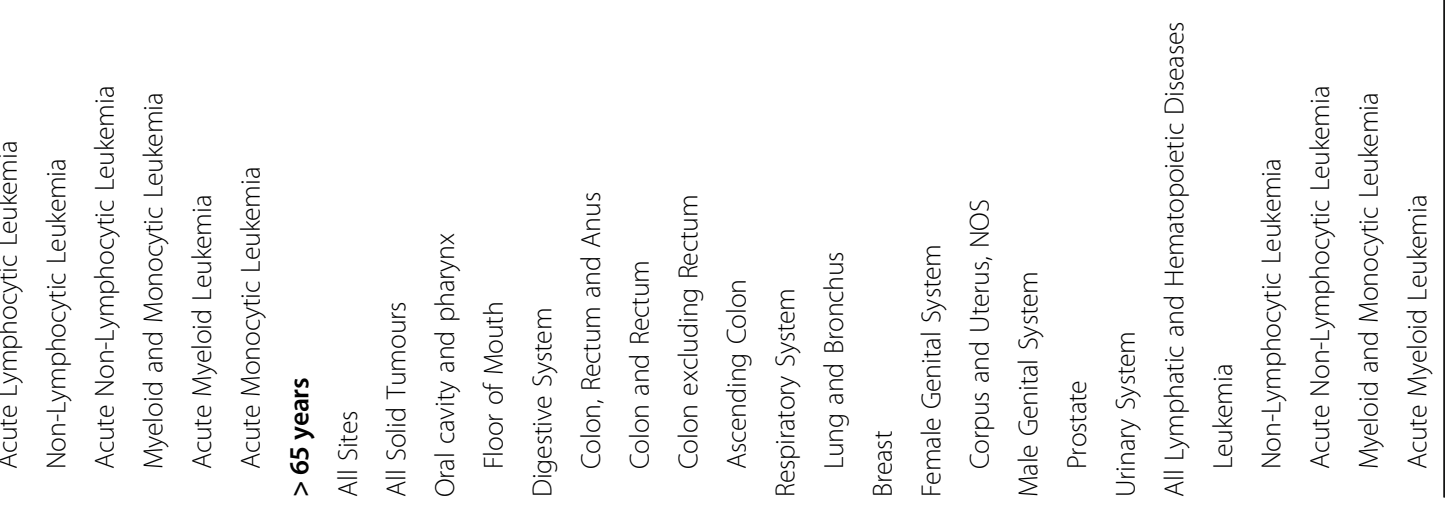
Table 6 Distribution of histology and stage in second primary lung cancer (SPLC) patients with history of an initial primary lung HGNEC

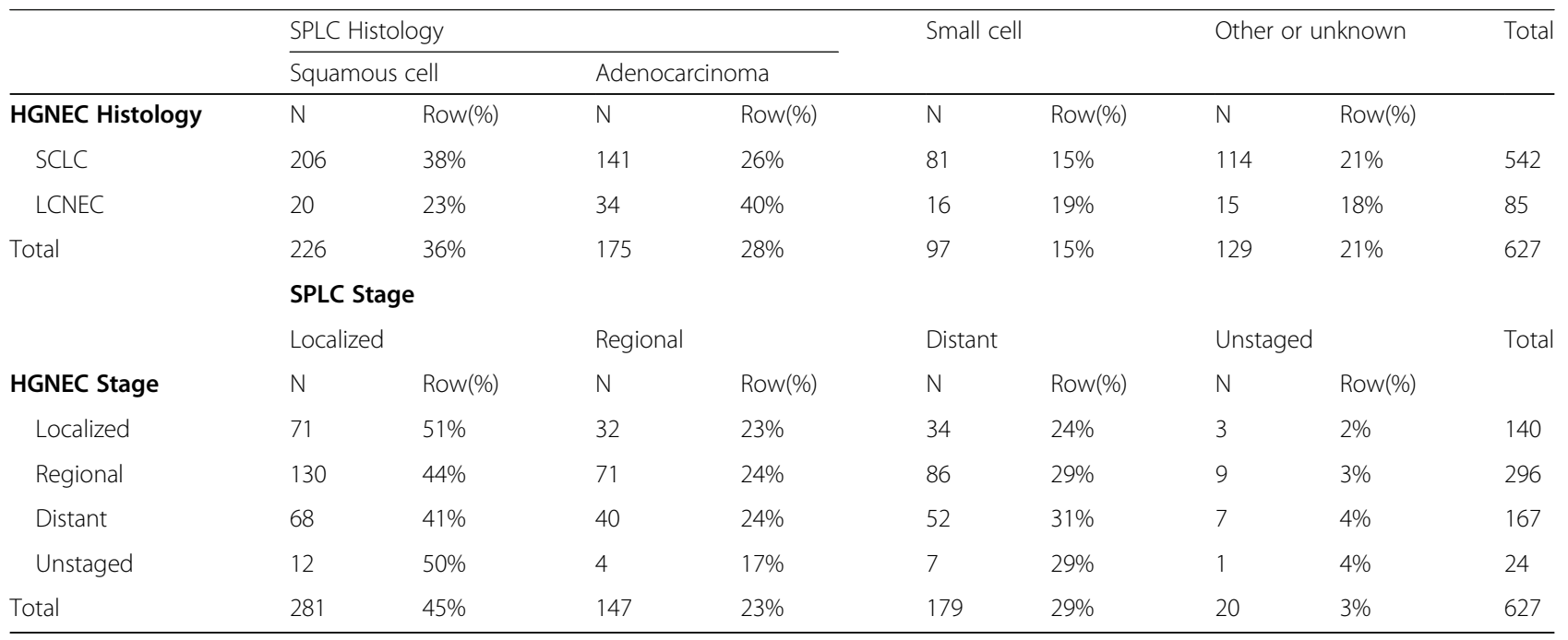

related malignancies. Many studies showed that acute myeloid leukemia and lung HGNEC have the same c-Kit high expression. Positivity expression of c-Kit is observed in $49 \%$ of LCNEC and $47 \%$ of SCLC cases [17], and the frequency of positive c-Kit among acute myeloid leukemia was about $80 \%$ [18]. However, there is no evidence to suggest that these two tumours are closely linked. Similarly, the relationship between lung HGNEC and acute myeloid leukemia has not been covered.

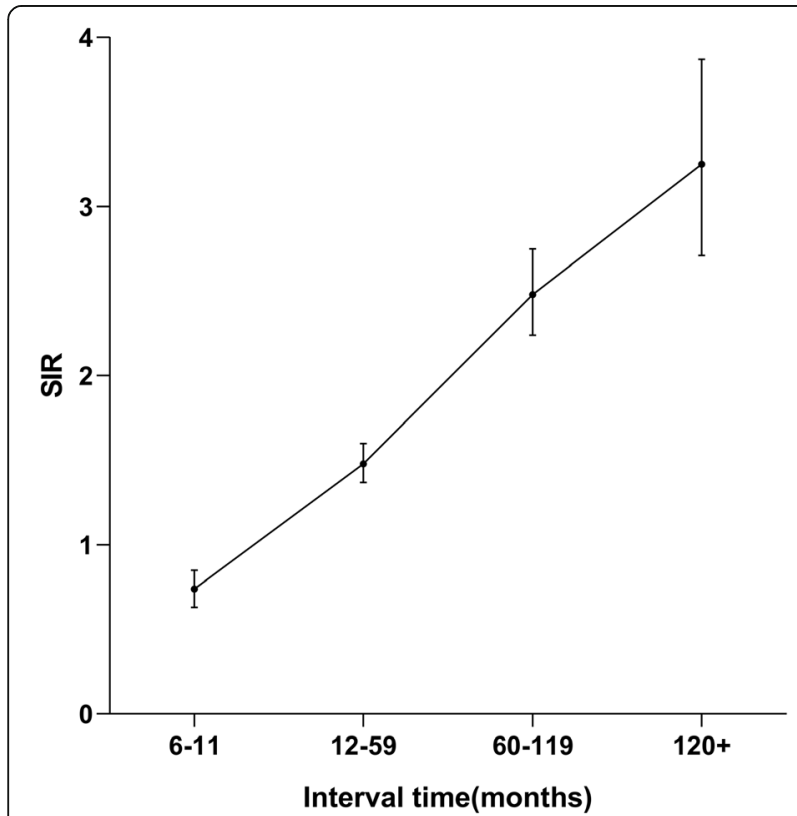

Fig. 2 Observed/expected (O/E) incidence (standardized incidence ratio, SIR) of second primary malignancies (SPMs) by latency period after the diagnosis of lung HGNEC over time
In lung cancers following pulmonary HGNEC, 74\% of SPLCs were found to be adenocarcinoma and squamous cell carcinoma. Much higher rates of squamous cell carcinoma were detected relative to the SCLC subset. To our knowledge, squamous and small cell histology are the most strongly related to smoking. This study supports our understanding of SCLC most closely linked to smoking [19]. Interestingly, lung cancers following lung LCNEC were much more likely to be of adenocarcinoma histology. However, based on currently observed data, we cannot identify the relationship between these two cancers. Thus, there is a need for advanced assessment techniques such as gene expression to provide information for patients and clinicians.

Multivariate Cox regression model revealed that older patients, advanced historical stage, beam radiation history, and shorter latency time were associated with increased risk of developing the SPMs in lung HGNEC patients. Our data found a higher risk of developing the SPMs to be in those aged more than 65. As expected, this is likely because older patients have a higher probability of developing invasive cancer. In addition, lung HGNEC has a high risk of death in the regional and distant stage. Beam radiation was strongly associated with increased overall mortality. A study demonstrated that radiotherapy, in combination with chemotherapy has been described as having an additive effect on the occurrence of secondary cancer [20]. However, our paper could not confirm this finding. Currently, there is no report about the long-term cause of death in patients with lung HGNEC. We also use the HR of cancer-specific survival to determine the impact of SPM on pulmonary HGNEC patients. The risk of cancer-specific mortality did not increase with age. This is because older patients 


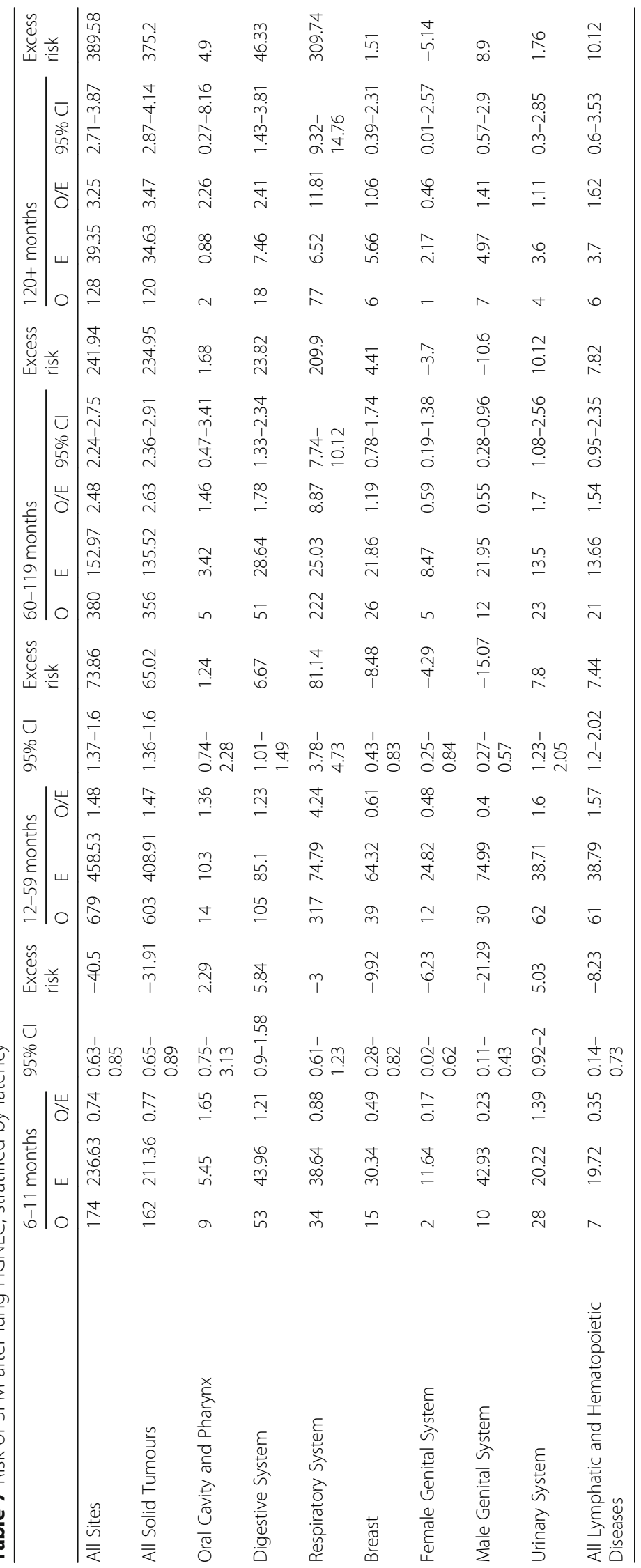


Table 8 Cox proportional hazard regression analysis for the overall survival and cancer-specific survival of lung HGNEC patients with SPM

\begin{tabular}{|c|c|c|c|c|c|c|}
\hline \multirow[t]{2}{*}{ Variable } & \multicolumn{3}{|c|}{ overall survival } & \multicolumn{3}{|c|}{ cancer-specific survival } \\
\hline & $\mathrm{HR}$ & $95 \% \mathrm{Cl}$ & P & $H R$ & $95 \% \mathrm{Cl}$ & $P$ \\
\hline \multicolumn{7}{|l|}{ Age } \\
\hline$<65$ year & & Reference & & & Reference & \\
\hline$\geq 65$ year & 1.242 & $1.085-1.422$ & 0.002 & 0.981 & $0.827-1.163$ & 0.824 \\
\hline \multicolumn{7}{|l|}{ Sex } \\
\hline Male & & Reference & & & Reference & \\
\hline Female & 0.962 & $0.843-1.098$ & 0.569 & 0.897 & $0.760-1.059$ & 0.198 \\
\hline \multicolumn{7}{|l|}{ Race } \\
\hline White & & Reference & & & Reference & \\
\hline Black & 0.922 & $0.727-1.169$ & 0.503 & 0.870 & $0.642-1.177$ & 0.366 \\
\hline Other & 1.011 & $0.712-1.434$ & 0.953 & 1.137 & $0.747-1.731$ & 0.550 \\
\hline \multicolumn{7}{|l|}{ Stage } \\
\hline Localized & & Reference & & & Reference & \\
\hline Regional & 1.608 & $1.317-1.964$ & 0.000 & 1.783 & $1.373-2.314$ & 0.000 \\
\hline Distant & 2.113 & $1.716-2.602$ & 0.000 & 2.370 & $1.809-3.103$ & 0.000 \\
\hline Unknown/unstaged & 1.230 & $0.835-1.811$ & 0.295 & 1.120 & $0.661-1.898$ & 0.674 \\
\hline \multicolumn{7}{|l|}{ Radiation } \\
\hline None/Unknown & & Reference & & & Reference & \\
\hline Beam radiation & 1.997 & $1.233-3.237$ & 0.005 & 2.254 & $1.299-3.909$ & 0.004 \\
\hline Other radiation & 0.991 & $0.833-1.178$ & 0.914 & 0.950 & $0.763-1.182$ & 0.643 \\
\hline \multicolumn{7}{|l|}{ Chemotherapy } \\
\hline Yes & & Reference & & & Reference & \\
\hline None/Unknown & 0.881 & $0.715-1.085$ & 0.232 & 0.915 & $0.704-1.190$ & 0.509 \\
\hline \multicolumn{7}{|l|}{ Latency } \\
\hline$\geq 60$ months & & Reference & & & Reference & \\
\hline 6-59 months & 3.862 & $3.310-4.507$ & 0.000 & 3.761 & $3.093-4.573$ & 0.000 \\
\hline
\end{tabular}

are more likely to die of other diseases such as cardiovascular disease.

The advantages of this research include a large sample size, which strengthens the generalizability of the findings. However, there are some limitations of the current study. The cross-sectional limitations rely on the retrospective nature and inherent limitations of publiclyaccessible databases, such as the lack of treatment details (radiation dosage, surgery type), family history, and lifestyle factors (smoking). Half of the data in some variables, such as grade, is unknown. These factors would affect the comprehensive analysis of risk factors for SPM development. Also, our analysis may have missed patients who change their living place throughout the follow-up period. Once they have SPMs, these details were not registered in the SEER database. Finally, germline mutations are not provided by the SEER database. Further research is required to identify the appropriate screening/surveillance recommendations and to clarify potential genetic factors that may lead to increased cancer risk for these patients.

\section{Conclusions}

The risk of SPM is significantly higher among lung HGNEC than the U.S. general population. The most common and biologically meaningful were acute monocytic leukemia, acute myeloid leukemia, and floor of mouth tumours, but an elevated risk for lung and oropharynx cancers was also demonstrated. Old age, advanced stage, beam radiation, and shorter latency time were identified as negative prognostic factors. Chemotherapy did not substantially influence the incidence of SPMs, which can be traced to the lack of adequate data. The observed increased risk may be explained by genetic susceptibility and lifestyle modifications. With the ongoing improvement in the long-term survival of patients with lung HGNEC, evaluation for SPMs will become even more crucial in the follow-up care of these patients. 


\section{Abbreviations}

HGNEC: High-grade neuroendocrine carcinoma; SPM: Second primary malignancy; SEER: Surveillance, Epidemiology and End Results; SIR: Standardized incidence ratio; AER: Absolute excess risk; SLCL: Small cell lung cancer; LCNEC: Large cell neuroendocrine carcinoma; OS: Overall survival; CSS: Cancer-specific survival; HR: Hazards ratio; Cl: Confidence interval; SPLC: Second primary lung cancer; TP53: Tumour suppressor protein 53; RB1: Retinoblastoma 1

\section{Acknowledgements}

The authors acknowledge the efforts of the SEER program tumour registries in the creation of the SEER database.

\section{Authors' contributions}

WXM contributed to study design. WXM and ZXJ collected the study data. WXM, CP, and TLL contributed to data analysis and interpretation. WXM contributed to manuscript writing. All authors have reviewed the study and approved the final version.

\section{Funding}

This work was supported by National Natural Science of China (No. 81802999). The funding bodies had no role in the design of the study and collection, analysis, and interpretation of data and in the writing of the manuscript.

\section{Availability of data and materials}

The datasets used and/or analyzed during the current study are available from the Surveillance, Epidemiology, and End Results (SEER) database (http:// seer.cancer.gov/data/sample-dua.html)

\section{Ethics approval and consent to participate}

Not applicable. Data is available in a public database; ethics approval is not applicable.

\section{Consent for publication}

Not applicable.

\section{Competing interests}

The authors made no disclosures.

\section{Author details}

'Department of Oncology, Yancheng No.1 People's Hospital, the Affiliated Hospital of Nanjing University, 166 Yulong West Road, Yancheng 224200, People's Republic of China. ${ }^{2}$ Department of Gynecologic Oncology, Zhejiang Cancer Hospital, Hangzhou 310000, People's Republic of China.

Received: 16 March 2020 Accepted: 27 July 2020

Published online: 03 August 2020

\section{References}

1. Allemani C, Weir HK, Carreira H, Harewood R, Spika D, Wang XS, et al. Global surveillance of cancer survival 1995-2009: analysis of individual data for 25,676,887 patients from 279 population-based registries in 67 countries (CONCORD-2). Lancet. 2015;385(9972):977-1010.

2. Bray F, Ferlay J, Soerjomataram I, Siegel RL, Torre LA, Jemal A. Global cancer statistics 2018: GLOBOCAN estimates of incidence and mortality worldwide for 36 cancers in 185 countries. CA Cancer J Clin. 2018;68(6):394-424.

3. Asamura H, Kameya T, Matsuno Y, Noguchi M, Tada H, Ishikawa Y, et al. Neuroendocrine neoplasms of the lung: a prognostic spectrum. J Clin Oncol. 2006;24(1):70-6

4. Thakur MK, Ruterbusch JJ, Schwartz AG, Gadgeel SM, Beebe-Dimmer JL, Wozniak AJ. Risk of second lung Cancer in patients with previously treated lung Cancer: analysis of surveillance, epidemiology, and end results (SEER) data. J Thorac Oncol. 2018;13(1):46-53.

5. Wu B, Cui Y, Tian J, Song X, Hu P, Wei S. Effect of second primary cancer on the prognosis of patients with non-small cell lung cancer. J Thorac Dis. 2019:11(2):573-82.

6. Wang S, Tang J, Sun T, Zheng X, Li J, Sun H, et al. Survival changes in patients with small cell lung cancer and disparities between different sexes, socioeconomic statuses and ages. Sci Rep. 2017;7(1):1339.
7. Schabath MB, Wu X, Vassilopoulou-Sellin R, Vaporciyan AA, Spitz MR. Hormone replacement therapy and lung cancer risk: a case-control analysis. Clin Cancer Res. 2004;10(1 Pt 1):113-23.

8. Yao Y, Gu X, Zhu J, Yuan D, Song Y. Hormone replacement therapy in females can decrease the risk of lung cancer: a meta-analysis. PLoS One. 2013;8(8):e71236.

9. Allemani C, Matsuda T, Di Carlo V, Harewood R, Matz M, Niksic M, et al. Global surveillance of trends in cancer survival 2000-14 (CONCORD-3): analysis of individual records for 37513025 patients diagnosed with one of 18 cancers from 322 population-based registries in 71 countries. Lancet. 2018:391(10125):1023-75.

10. Deng C, WU SG, Tian Y. Lung large cell neuroendocrine carcinoma: an analysis of patients from the surveillance, epidemiology, and end-results (SEER) database. Med Sci Monit. 2019;25:3636-46.

11. Abdel-Rahman O, Cheung WY. Subsequent thoracic cancers among patients diagnosed with lung cancer: a SEER database analysis. Curr Med Res Opin. 2017;33(11):2009-17.

12. Khanal A, Lashari BH, Kruthiventi S, Arjyal L, Bista A, Rimal P, et al. The risk of second primary malignancy in patients with stage la non-small cell lung cancer: a U.S. population-based study. Acta Oncol. 2018;57(2):239-43.

13. Iwakawa R, Kohno T, Totoki Y, Shibata T, Tsuchihara K, Mimaki S, et al. Expression and clinical significance of genes frequently mutated in small cell lung cancers defined by whole exome/RNA sequencing. Carcinogenesis. 2015;36(6):616-21.

14. D'Amico D, Carbone D, Mitsudomi T, Nau M, Fedorko J, Russell E, et al. High frequency of somatically acquired p53 mutations in small-cell lung cancer cell lines and tumors. Oncogene. 1992;7(2):339-46.

15. George J, Walter V, Peifer M, Alexandrov LB, Seidel D, Leenders F, et al. Integrative genomic profiling of large-cell neuroendocrine carcinomas reveals distinct subtypes of high-grade neuroendocrine lung tumors. Nat Commun. 2018;9(1):1048.

16. Poeta ML, Manola J, Goldwasser MA, Forastiere A, Benoit N, Califano JA, et al. TP53 mutations and survival in squamous-cell carcinoma of the head and neck. N Engl J Med. 2007;357(25):2552-61.

17. Matsumura $Y$, Umemura S, Ishii G, Tsuta K, Matsumoto S, Aokage $K$, et al. Expression profiling of receptor tyrosine kinases in high-grade neuroendocrine carcinoma of the lung: a comparative analysis with adenocarcinoma and squamous cell carcinoma. J Cancer Res Clin Oncol. 2015;141(12):2159-70.

18. Ikeda H, Kanakura Y, Tamaki T, Kuriu A, Kitayama H, Ishikawa J, et al. Expression and functional role of the proto-oncogene c-kit in acute myeloblastic leukemia cells. Blood. 1991;78(11):2962-8.

19. Socinski MA, Obasaju C, Gandara D, Hirsch FR, Bonomi P, Bunn P, et al. Clinicopathologic features of advanced squamous NSCLC. J Thorac Oncol. 2016;11(9):1411-22.

20. Dores GM, Metayer C, Curtis RE, Lynch CF, Clarke EA, Glimelius B, et al. Second malignant neoplasms among long-term survivors of Hodgkin's disease: a population-based evaluation over 25 years. J Clin Oncol. 2002; 20(16):3484-94.

\section{Publisher's Note}

Springer Nature remains neutral with regard to jurisdictional claims in published maps and institutional affiliations.

Ready to submit your research? Choose BMC and benefit from:

- fast, convenient online submission

- thorough peer review by experienced researchers in your field

- rapid publication on acceptance

- support for research data, including large and complex data types

- gold Open Access which fosters wider collaboration and increased citations

- maximum visibility for your research: over $100 \mathrm{M}$ website views per year

At $\mathrm{BMC}$, research is always in progress.

Learn more biomedcentral.com/submission 